\title{
Dynamic tests of composite footbridge segment - experimental and numerical studies
}

\author{
Tomasz Wiczenbach ${ }^{1}$, Tomasz Ferenc ${ }^{1 *}$, Lukasz Pyrzowski ${ }^{1}$, and Jacek Chróścielewski ${ }^{1}$ \\ ${ }^{1}$ Faculty of Civil and Environmental Engineering, Gdansk University of Technology, Poland
}

\begin{abstract}
Experimental dynamic tests and numerical simulations of a 3 meters long segment of a footbridge made of polymer composites are presented in the paper. The span-length is reduced, however dimensions of cross-section are the same as the target footbridge. The segment structure is made of sandwich panels, which consist of fibre reinforced polymer (GFRP) laminates (skins) and a PET foam (core). The first part of the paper contains description and results of experimental dynamic tests, which were subjected to the structure. The excitations during these tests was realised by a group of people standing or jumping on the structure deck. The obtained results allowed to determine natural frequencies as well as damping ratios. Moreover, cyclic loading was applied to the structure deck to check the possibility of delamination or debonding occurrence, as a result of repetitive dynamic excitations. The second part contains validation of numerical model - results of numerical analysis and its comparison with the experimental ones.
\end{abstract}

\section{Introduction}

Nowadays, requirements for modern structure often force the use of new materials. In order to design structure made from untraditional material, like composites studied in the paper, it is obligatory to make more sophisticated analysis compared to the one made from traditional ones like steel or concrete. Material characteristics of composites are not standardised and often depend on many factors like components used in production as well as manufacturing process itself. First of all it is necessary to conduct experimental tests that allow to identify material parameters. Moreover, it is also obligatory to check correctness of assumptions made during numerical analysis by conducting validation test [1-2].

In the paper the investigation of dynamic behaviour of the structure which is thought to be a 3 metres long segment of GFRP composite footbridge is presented (Fig. 1a). The dynamic analysis is crucial for very light footbridges [3]. Their small mass results low natural frequencies that are close to the critical frequencies of dynamic excitations produced by pedestrians. The presented research was a starting point for the analysis of the target full-length footbridge (Fig. 1b). The study is a part of project FOBRIDGE realized in years 2013-2015 by consortium of Gdansk University of Technology (main leader), Military University of Technology in Warsaw and the private company ROMA Co. Ltd.

* Corresponding author: tomasz.ferenc@pg.edu.pl 
The main aim of the study, was to construct a single span footbridge made only of composite materials as one element in a single technological process [4-6].

(a)

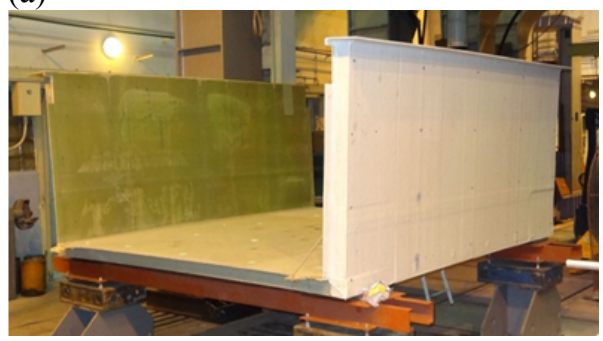

(b)

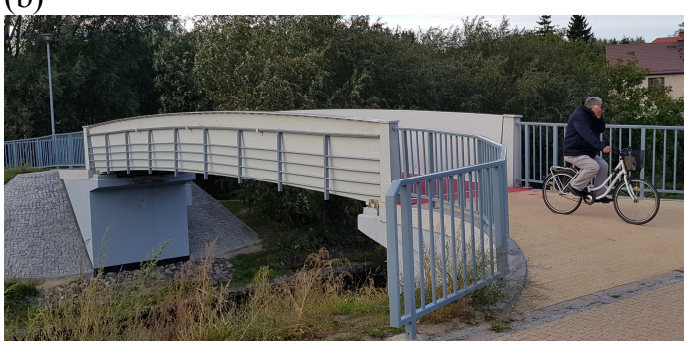

Fig. 1. Side views: (a) analysed segment, (b) target footbridge.

\section{Description of segment}

The structure of analysed segment (Fig. 1a) is a sandwich type. Its GFRP laminate skins are made of vinyl ester resin reinforced with six layers of two-directional glass fabrics. The thickness of a single layer is $0.663 \mathrm{~mm}$, hence the thickness of the entire laminate is $3.978 \mathrm{~mm}$. The density was assumed as $1.71 \mathrm{~g} / \mathrm{cm}^{3}$. The core is made of a PET foam. The thickness of the foam is $100 \mathrm{~mm}$, and the density is $100 \mathrm{~kg} / \mathrm{m}^{3}$. Material parameters are listed in table 1 for single lamina [7] and in table 2 for PET foam, respectively.

Table 1. Material parameters for lamina [7].

\begin{tabular}{|l|l|l|l|l|}
\hline \multicolumn{2}{|l|}{ Parameter } & Description & value & unit \\
\hline$E_{1}$ & $E_{2}$ & longitudinal (1) and transverse (2) elastic moduli & 23.4 & {$[\mathrm{GPa}]$} \\
\hline$v_{12}$ & Poisson's ratio & 0.153 & {$[-]$} \\
\hline$G_{12}$ & & in-plane shear modulus & 3.52 & {$[\mathrm{GPa}]$} \\
\hline$G_{13}$ & $G_{23}$ & transverse shear moduli & 1.36 & {$[\mathrm{GPa}]$} \\
\hline
\end{tabular}

Table 2. Material parameters for PET foam.

\begin{tabular}{|l|l|l|l|}
\hline Parameter & Description & value & unit \\
\hline$E$ & elastic modulus & 70 & {$[\mathrm{MPa}]$} \\
\hline$v_{12}$ & Poisson's ratio & 0.4 & {$[-]$} \\
\hline
\end{tabular}

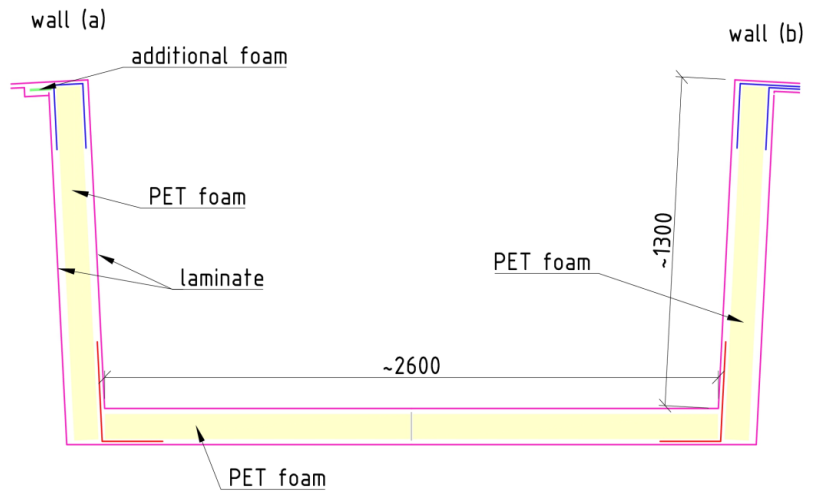

Fig. 2. Cross-section of segment [mm]. 
Segment has the same cross-section as the target footbridge (Fig. 2), its total length is reduced to 3 metres, thus theoretical length is $2.5 \mathrm{~m}$. The usable width of segment is $2.59 \mathrm{~m}$ and the height of handrails is $1.3 \mathrm{~m}$. The dimensions of cross-section are adopted in accordance with the polish standards. Additionally, segment is not symmetric, parapet in wall (a) is strengthened by an additional $10 \mathrm{~mm}$ PET foam. During tests the segment was situated on four rubber bearings with dimensions of $300 \times 300 \times 30 \mathrm{~mm}$.

The main aim of segment behaviour study was to validate numerical model that would be used in further design process of a target footbridge with length of 14 meters. Moreover, manufacturing of segment itself was also a technological test. Segment, the same as the target footbridge, was produced as a single element in one cycle of the infusion process.

\section{Conducted experiments}

To obtain measured values the following instrumentation have been installed: strain gauges $(\mathrm{T})$ and displacement sensors (U). Location of this sensors is shown in Fig. 3. Additionally, the lines indicate the direction of the measured values.

(a)

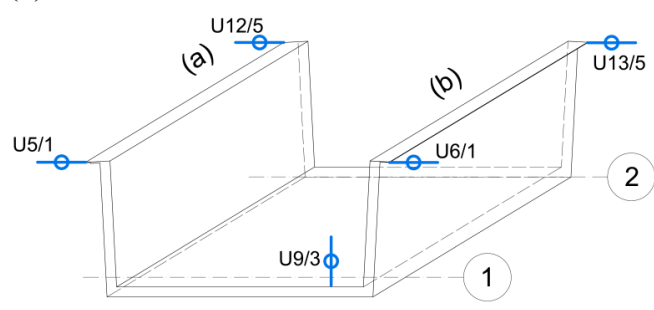

(b)



Fig. 3. Location of devices: (a) displacements sensors $U$, (b) strain gauges $\mathrm{T}$.

\subsection{Dynamic loading - group of six people}

The segment was subjected by dynamic loading. For static test examination see [8-9]. Scheme S1 (Fig. 4a) consisted of forces applied on the platform slab realized by a group of six people with a total weight of $4.8 \mathrm{kN}$. The course of the test can be observed on the graph presenting vertical displacement at the midpoint of the platform (point U9/3) in a function of time (Fig. 4b).

(a)

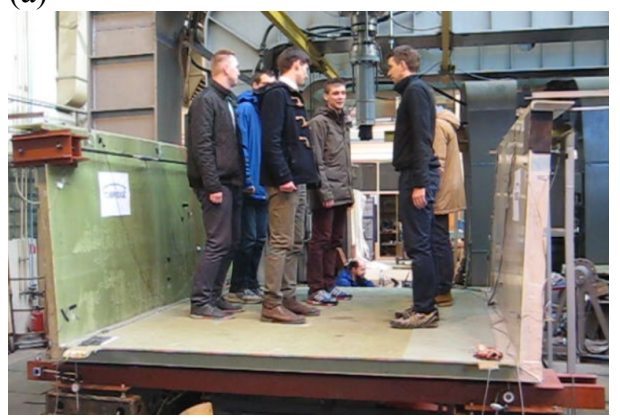

(b)

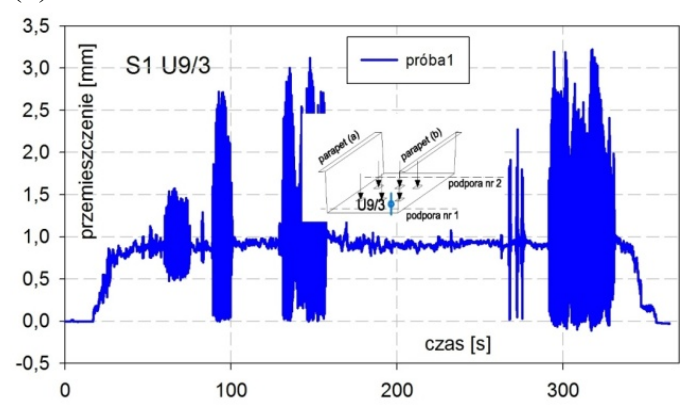

Fig. 4. Load test S1: (a) excitation, (b) displacement in point U9/3.

Conducted experiments allowed to determine the dynamic characteristics of the segment. Using the fast Fourier transform (FFT), it was possible to determine the natural 
frequencies. Based on the displacement time history registered at point U5/1 (Fig. 5a) and U12/1 (Fig. 6a) for wall (a) and U6/1 (Fig. 7a) and U13/5 (Fig. 8a) for wall (b), the Fourier transform was conducted (Figs. 5b-8b).

(a)

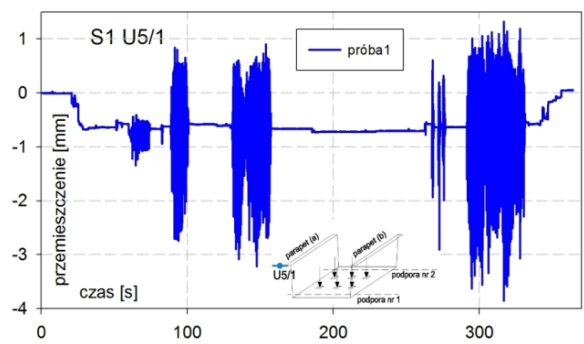

(b)



Fig. 5. Scheme S1, point U5/1: (a) acceleration-time relation, (b) Fourier transform.

(a)

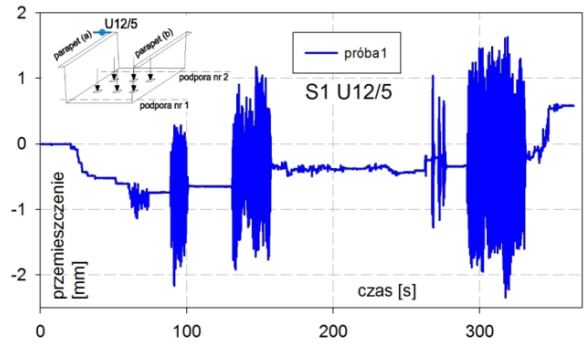

(b)

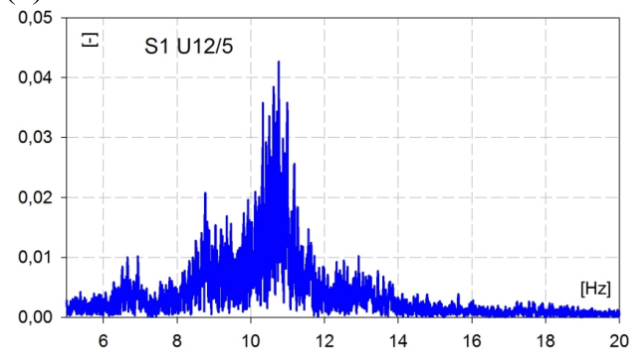

Fig. 6. Scheme S1, point U12/5: (a) acceleration-time relation, (b) Fourier transform.

(a)

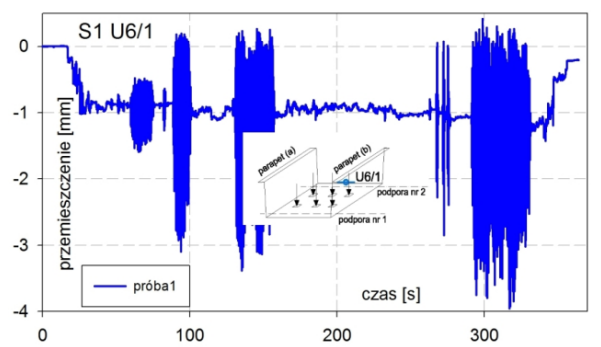

(b)

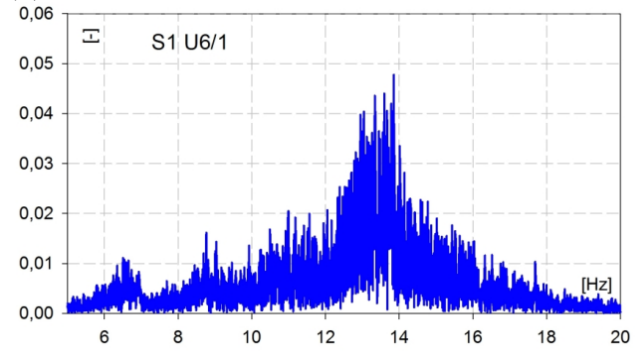

Fig. 7. Scheme S1, point U6/1: (a) acceleration-time relation, (b) Fourier transform.

(a)

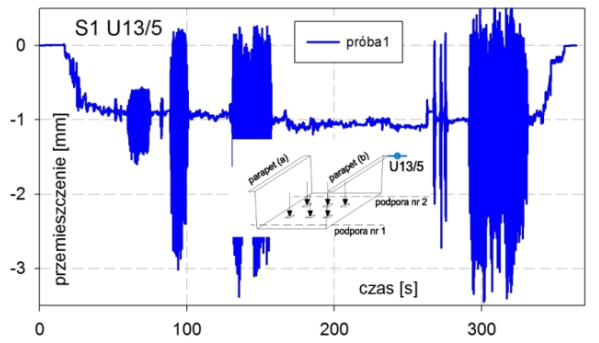

(b)

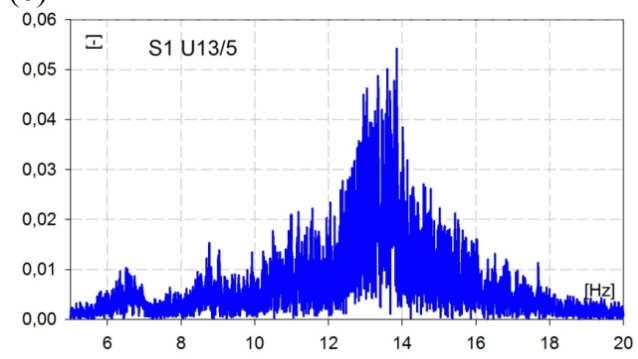

Fig. 8. Scheme S1, point U13/5: (a) acceleration-time relation, (b) Fourier transform. 
The obtained values of natural frequencies are presented in table 3. Two different values of the natural vibration frequencies result from non-symmetrical structure of the segment (parapet strengthening on one side).

Table 3. Scheme S1: Natural frequencies.

\begin{tabular}{|c|c|c|}
\hline Point & Localization & $\begin{array}{c}\text { Frequency } \\
{[\mathrm{Hz}]}\end{array}$ \\
\hline $\mathrm{U} 5 / 1$ & wall (a) & 10.6 \\
\hline $\mathrm{U} 12 / 5$ & wall (a) & 10.7 \\
\hline $\mathrm{U} 6 / 1$ & wall (b) & 13.9 \\
\hline $\mathrm{U} 13 / 5$ & wall (b) & 13.9 \\
\hline
\end{tabular}

Based on the research, by measuring the amplitude of vibrations in subsequent cycles, it was possible to estimate logarithmic damping decrement $\delta$ and hence damping ratio $\xi$, in accordance with the formula (for small values of damping ratio):

$$
\delta=\frac{1}{j} \ln \frac{u_{i}}{u_{i+j}}=\frac{2 \pi \xi}{\sqrt{1-\xi^{2}}} \rightarrow \xi \cong \frac{\delta}{2 \pi}
$$

where $j-$ no. of cycles, $u_{i}-$ amplitude of vibration in the $i$-th cycle, $u_{i+j}-$ the vibration amplitude in $(i+j)$-th cycle.

The values of the damping ratios that were obtained by analysing the displacements at the points $\mathrm{U} 5 / 1, \mathrm{U} 6 / 1, \mathrm{U} 12 / 5$ and $\mathrm{U} 13 / 5$ is summarized in table 4.

Table 4. Logarithmic decrement of damping and damping ratio.

\begin{tabular}{|c|c|c|}
\hline Point & Logarithmic decrement of damping & Damping ratio \\
\hline U5/1 & 0.327 & 0.052 \\
\hline U12/5 & 0.188 & 0.03 \\
\hline U6/1 & 0.390 & 0.062 \\
\hline U13/5 & 0.320 & 0.051 \\
\hline av. & 0.306 & 0.049 \\
\hline
\end{tabular}

\subsection{Dynamic loading - cyclic force}

During the cyclic test the segment was subjected to a single force load with frequency of $1 \mathrm{~Hz}$. The load was applied in the middle of the deck by a hydraulic piston, see Fig. 9.

(a)



(b)

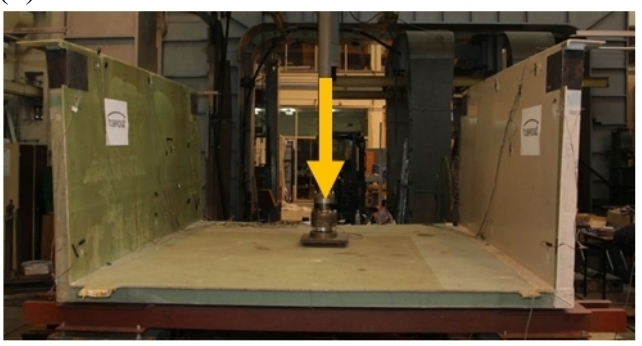

Fig. 9. Scheme of cyclic force application. 
The main purpose of conducted experiment was to investigate if potentially delamination in laminate or debonding in sandwich structure occur. Hence, 30000 cycles of harmonic force was applied, with range from $12 \mathrm{kN}$ to $50 \mathrm{kN}$. Displacements and strains in several points (Fig. 3) were measured. The examples of displacement time history from different ranges of the test in measuring point U9/3 are shown in Fig. 10. As it can be observed, the structural response caused by harmonic excitation also give harmonic function. The range of displacement is from about $4 \mathrm{~mm}$ to $14 \mathrm{~mm}$ and almost do not change through the experiment. No external and internal failures of the structure were observed during all the conducted tests, as well as later after cutting the segment into pieces.
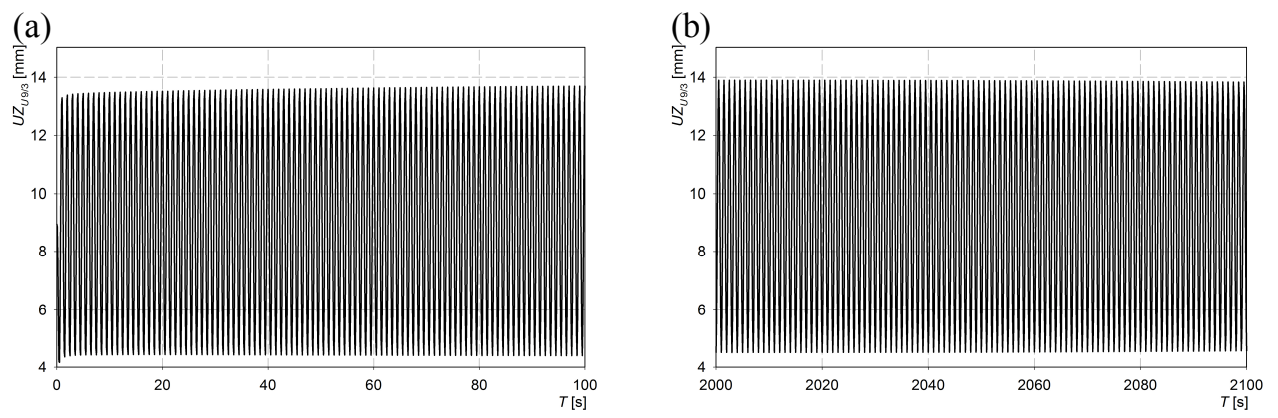

Fig. 10. Displacements in point U9/3: (a) 0-100 cycles range, (b) 2000-2100 cycles range.

\section{Numerical simulations}

The numerical model of the analysed segment was made in the FEMAP with Nastran software with using the finite element method FEM (Fig. 11).

(a)

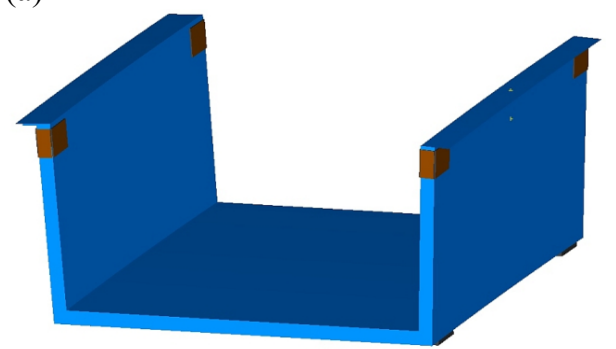

(b)

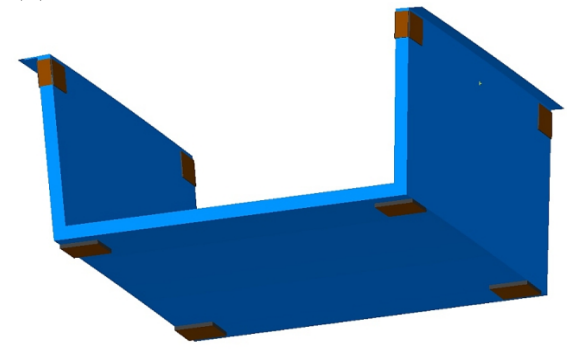

Fig. 11. Visualization of the FEM model: (a) general view, (b) general view from below.

Laminates were modelled as multi-layered shells while PET as solid elements. Moreover, laminates were modelled by means of equivalent single layer (ESL) theory, where 3D laminate is simplified by 2D shell. Material parameters were assumed according to tables 1-2 for single lamina and PET foam, respectively. Four-node element were used for shells with linear shape functions and full integration, while for solids eight-node element also with liner shape functions and full integration. The characteristic dimension of the finite element is assumed at the level of about $25 \mathrm{~mm}$, which gives four elements through the thickness of the sandwich structure in the deck, and five elements in the walls. 
Thus, the total number of finite elements in the model is 199498 , while the number of nodes is 157401 .

After model analysis was conducted, the first four mode shapes and natural frequencies was determined and shown in Fig. 12. They were determined in two approaches: the first one without considering mass of group of people standing on the deck and the second one taking into account that mass. The first frequency was obtained as $12.31 \mathrm{~Hz}$ without mass and $11.24 \mathrm{~Hz}$ with mass, the second as $16.34 \mathrm{~Hz}$ with and $13.60 \mathrm{~Hz}$ without mass, the third as $20.66 \mathrm{~Hz}$ with and $15.31 \mathrm{~Hz}$ without mass, and the fourth $30.18 \mathrm{~Hz}$ with and $17.94 \mathrm{~Hz}$ without mass. The results confirmed asymmetric structure response, Fig. 12a shows the first mode shape where wall (a) vibrates, while Fig. 12b shows vibrations of wall (b).

(a)

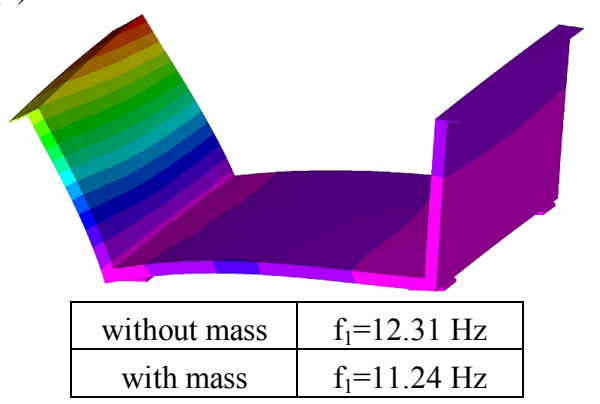

(c)

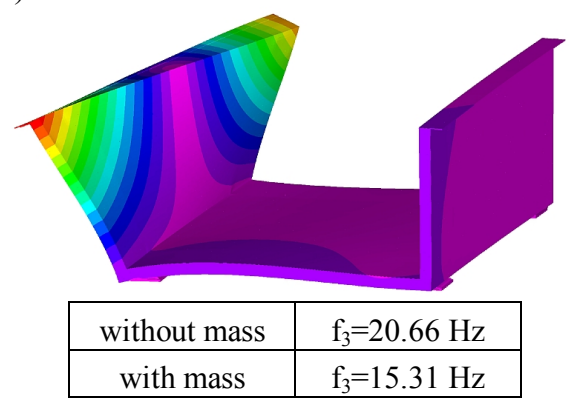

(b)

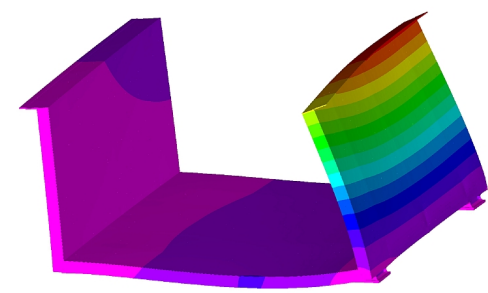

\begin{tabular}{|c|c|}
\hline without mass & $\mathrm{f}_{2}=16.34 \mathrm{~Hz}$ \\
\hline with mass & $\mathrm{f}_{2}=13.60 \mathrm{~Hz}$ \\
\hline
\end{tabular}

(d)

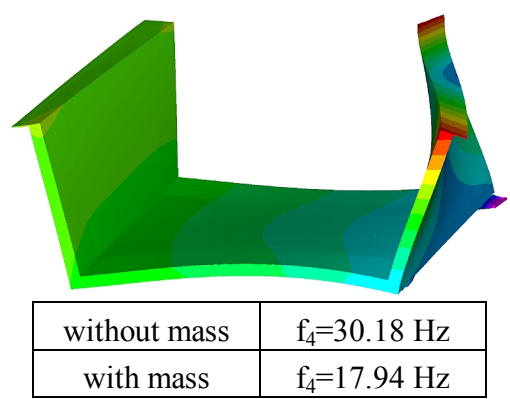

Fig. 12. Mode shapes and natural frequencies: (a) first, (b) second, (c) third, (d) fourth.

\section{Conclusions}

In the paper, authors focused on analysis of 3 meters long segment of the target footbridge made fully of composite materials. The segment was studied in an aspect of its dynamic behaviour. Parameters such as natural frequencies and damping ratios were determined.

The results presented in this paper were based on experimental tests supported by numerical simulations. Asymmetric cross-section can cause various frequencies of free vibrations of two different walls (a) and (b). The natural frequencies of segment obtained from experimental results were estimated as $10.7 \mathrm{~Hz}$ in the wall (a) and $13.9 \mathrm{~Hz}$ in the wall (b). Values for numerical models are various according to approach - whether mass is taken into account or not. The obtained values compared with experimental results are listed in table 5 . 
Table 5. Comparison of natural frequencies.

\begin{tabular}{|c|c|c|c|}
\hline \multirow{2}{*}{ wall } & \multirow{2}{*}{ experiment } & \multicolumn{2}{|c|}{ numerical model } \\
\cline { 3 - 4 } & & without mass & with mass \\
\hline (a) & 10.65 & 12.31 & 11.24 \\
\hline (b) & 13.9 & 16.34 & 13.60 \\
\hline
\end{tabular}

Some differences of values obtained in experimental and numerical part could be caused by few reasons. First of all, oscillations in experiment were excited by jumps of group of people. As it is shown, there is significant difference whether their mass is considered or not. More accurate results were obtained with mass. Furthermore, boundary conditions also can affect behaviour of structure. It was assumed, that segment is rigidly connected to rubber bearings. In fact, during vibrations segment could lose contact between itself and bearings.

As it was presented, developed modelling method of shell and sandwich type structure gave satisfying results - the model was positively validated (see also [8-9]) and after expansion was successfully used to design target composite footbridge [4-5].

\section{References}

1. Pyrzowski Ł., Sobczyk B., Witkowski W., Chróścielewski J. (2016) Three-point bending test of sandwich beams supporting the GFRP footbridge design process validation. 3rd Polish Congress of Mechanics (PCM) / 21st International Conference on Computer Methods in Mechanics (CMM), Taylor \& Francis Group, 489-492

2. Siwowski T., Kaleta D., Rajchel M. (2018) Structural behaviour of an all-composite road bridge. Composite Structures, 192, 555-567

3. Drygala I.J., Polak M.A., Dulinska J.M. (2019) Vibration serviceability assessment of GFRP pedestrian bridges, Engineering Structures, 184, 176-185

4. Chróścielewski J., Miśkiewicz M., Pyrzowski Ł., Sobczyk B., Wilde K. (2017) A novel sandwich footbridge - Practical application of laminated composites in bridge design and in situ measurements of static response, Composites Part B 126, 153-161

5. Chróścielewski J., Miśkiewicz M., Pyrzowski Ł., Rucka M., Sobczyk B., Wilde K (2018) Modal properties identification of a novel sandwich footbridge - Comparison of measured dynamic response and FEA, Composites Part B 151, 245-255

6. Ferenc T., Pyrzowski Ł., Chróścielewski J., Mikulski T. (2018) Sensitivity analysis in designing process of sandwich U-shaped composite footbridge, Shell Structures: Theory and Applications. - Vol. 4, ed. W. Pietraszkiewicz, W. Witkowski, Leiden: CRC Press/Balkema, 413-416

7. Klasztorny M., Gotowicki P., Nycz D. 2013. Identification tests of new soaked composite BG/F in temperature $20^{\circ} \mathrm{C}$, Report 6-2013v4 of project Fobridge, (in Polish)

8. Miśkiewicz M., Daszkiewicz K., Ferenc T., Witkowski W., Chróścielewski J. (2016) Experimental tests and numerical simulations of full scale composite sandwich segment of a foot- and cycle- bridge. Advances in Mechanics: Theoretical, Computational and Interdisciplinary Issues, 2016, Taylor \& Francis Group, 401-404

9. Chróścielewski J., Ferenc T., Mikulski T., Miśkiewicz M., Pyrzowski Ł. (2019) Numerical modeling and experimental validation of full-scale segment to support design of novel GFRP footbridge, Composite Structures, 213, 299-307 